ARTICLE

https://doi.org/10.1038/s41467-019-13611-6

\title{
Acyl radical to rhodacycle addition and cyclization relay to access butterfly flavylium fluorophores
}

Jiangliang Yin ${ }^{1}$, Yuming Zhang ${ }^{1}$, Jian Li ${ }^{1}$, Lei Zhu ${ }^{2}$, Yu Lan ${ }^{2}$ \& Jingsong You ${ }^{1 \star}$

Transition metal-catalyzed $\mathrm{C}-\mathrm{H}$ activation and radical reactions are two versatile strategies to construct diverse organic skeletons. Here we show the construction of a class of flavylium fluorophores via the merge of radical chemistry and $\mathrm{C}-\mathrm{H}$ activation starting from (hetero)aryl ketones and alkynes. This protocol is not only applicable to aryl ketones but also to heteroaryl ketones such as thiophene, benzothiophene and benzofuran, thus leading to structural diversity. Mechanism studies, including control experiments, intermediate separation, radical trapping, EPR and ESI-HRMS experiments, demonstrate that the key step lies in the addition of the acyl radical generated by the copper-catalyzed $\mathrm{C}-\mathrm{C}$ bond cleavage of aryl ketone to the rhodacycle formed via the $\mathrm{C}-\mathrm{H}$ activation of aryl ketone. The flavylium fluorophores feature butterfly symmetrical configuration, nearly planar skeleton and delocalized positive charge, and exhibit intriguing photophysical properties, such as tunable absorption and emission wavelengths and high quantum yields.

\footnotetext{
${ }^{1}$ Key Laboratory of Green Chemistry and Technology of Ministry of Education, College of Chemistry, Sichuan University, 29 Wangjiang Road, 610064 Chengdu, PR China. ${ }^{2}$ School of Chemistry and Chemical Engineering, Chongqing University, 400030 Chongqing, PR China. *email: jsyou@scu.edu.cn
} 
$\mathrm{D}$ ue to attractive electronic, optical, electrochemical and magnetic properties, organic fluorophores have been considered as promising candidates for applications, such as fluorescent markers, photosensitizers, nonlinear optical materials and nano-electronic devices ${ }^{1-13}$. Therefore, diverse kinds of organic fluorophores have been discovered and developed, among which nitrogen-based porphyrins ${ }^{1,2}$, BODIPYs $^{3-5}$ and cyanine derivatives 6,7 exhibit extensive and outstanding properties (Fig. 1a). In recent years, oxygen-doped fluorophores based on pyrylium framework begin to attract attention because of tunable emission wavelength, high quantum yield and water solubility, making them as ideal optical-imaging reagents (Fig. 1b) ${ }^{8-13}$. From both the fundamental and application viewpoints, a study of the structural diversity of organic fluorophores is doubtlessly of great importance.

Transition metal-catalyzed $\mathrm{C}-\mathrm{H}$ activation and radical reactions have been developed as two versatile tools for the construction of organic functional skeletons ${ }^{14-35}$. The metalcatalyzed $\mathrm{C}-\mathrm{H}$ activation reactions proceed via the formation of carbon-metal bond, typically classified as charged speciesinvolving ionic reactions, while the key step of the radical reactions involves an electrophilic addition of a radical species to arene, alkene, or alkyne. Undoubtedly, the combination of ionic and radical reactions would create new chemical transformations and thereby produce complex molecules with high reaction efficiency. Despite an appealing strategy, it is challenging to achieve a well-organized reaction relay because the presence of the highly reactive radical species may give rise to an uncontrollable, complicated reaction process. Given the weak coordinating ability and keto-enol tautomerism, as well as easily being oxidized to radical species, aryl ketones are considered as an ideal element to implement diverse chemical transformations $s^{20-23,32,33}$. By using aryl ketones and alkynes as substrates, Glorius and Cheng independently reported the rhodium-catalyzed $\mathrm{C} 2-\mathrm{H}$ activation/ annulation reactions to deliver indenol and fulvene derivatives 20,21 . In our previous work, carbohelicenes were synthesized by a $\mathrm{C}-\mathrm{H}$ activation/radical approach/C-H activation relay of $\alpha$-acetylnaphthalenes with alkynes ${ }^{35}$.

Herein, we describe the addition of an acyl radical generated by the copper-catalyzed sequential oxidation/C-C bond cleavage of (hetero)arylketones to the rhodacycle to produce butterfly flavylium fluorophores (BFFs) with symmetrical and nearly planar skeleton with delocalized positive charge (Fig. 2).

\section{Results}

Analysis of structure and DFT calculation. In the investigation of the reaction of 4-methoxyacetophenone with diphenylacetylene, the BFF 3aa was unexpectedly isolated in $8 \%$ yield by using $5 \mathrm{~mol} \%$ of $\left[\mathrm{Cp}^{*} \mathrm{RhCl}_{2}\right]_{2}$ as the catalyst, $\mathrm{Ag}_{2} \mathrm{O}$ as the oxidant, $\mathrm{Cu}$ $(\mathrm{OAc})_{2} \cdot \mathrm{H}_{2} \mathrm{O}$ as the additive, and DCE as the solvent in the presence of $20 \mathrm{~mol} \%$ of $\mathrm{AgSbF}_{6}$ at $150^{\circ} \mathrm{C}$ (Supplementary Table 1, entry 1). X-ray single crystal analysis of 3aa shows a nearly planar skeleton with a little angle of $11.6^{\circ}$ between the two pyrylium rings (Fig. 3a, b). The length of $\mathrm{C} 2-\mathrm{C} 3$ bond $(1.389(5) \AA$ ) is close to that of $\mathrm{C} 3-\mathrm{C} 4$ bond $(1.372(5) \AA)$, which are between the lengths of $\mathrm{C}-\mathrm{C}$ single bond $(1.455 \AA)$ and $\mathrm{C}=\mathrm{C}$ double bond $(1.326 \AA)^{36}$. The ${ }^{1} \mathrm{H}$ NMR spectrum of 3aa shows a symmetrical configuration, suggesting that the positive charge is delocalized equally around the skeleton. In addition, density functional theory (DFT) calculation was employed to evaluate the intrinsic characteristic of cationic 3aa (Supplementary Data 1) 37,38. As $^{37}$ shown in Fig. 3c, d, the natural population analysis and natural bond orbital (NBO) atomic charge distribution further illustrate that the positive charge of $\mathbf{3 a a}$ is mostly delocalized by the two pyrylium rings.

Optimization of the reaction conditions. With the butterfly flavylium scaffold in hand, optimization of the reaction conditions was next conducted (Supplementary Table 1). Considering the zwitterionic form of the product, 1.5 equivalents of $\mathrm{NaSbF}_{6}$ were added into the reaction system, improving the yield of $\mathbf{3 a a}$ to $45 \%$ (Supplementary Table 1, entry 3). The copper salt is important for this reaction and no desired product could be detected without the addition of copper salt (Supplementary Table 1, entry 4). Subsequently, various copper species, such as $\mathrm{CuBr}_{2}, \mathrm{CuO}, \mathrm{CuCl}, \mathrm{Cu}\left(\mathrm{OAc}\right.$ ), and $\mathrm{Cu}_{2} \mathrm{O}$ were screened (Supplementary Table 1, entries 5-9). 3aa was obtained in $49 \%$ yield when $0.04 \mathrm{mmol}$ of $\mathrm{Cu}(\mathrm{OAc})_{2} \cdot \mathrm{H}_{2} \mathrm{O}$ was used (Supplementary Table 1, entry 10). Oxidant $\mathrm{Ag}_{2} \mathrm{CO}_{3}$ could further improve the yield of 3aa to $63 \%$ (Supplementary Table 1, entry 15). Solvents are critical for this reaction and other solvents, such as toluene,

a Nitrogen-based fluorophores

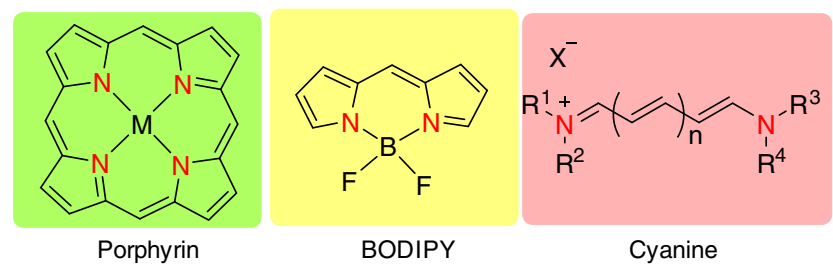

b Oxygen-based fluorophores

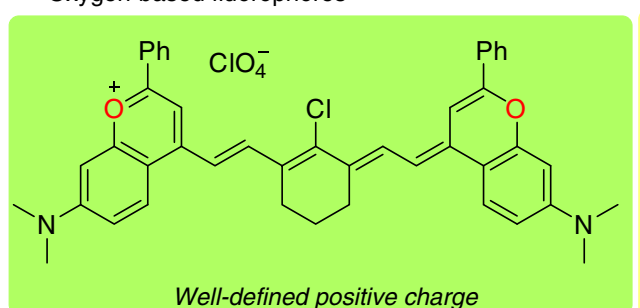

Favylium polymethine fluorophore (Sletten, 2017)

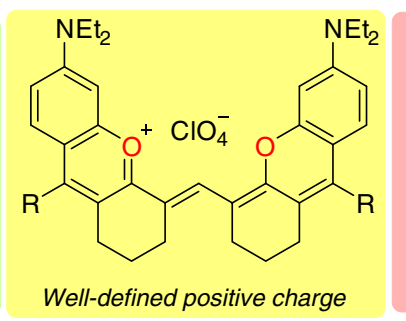

CX-1

(Zhang, 2019)

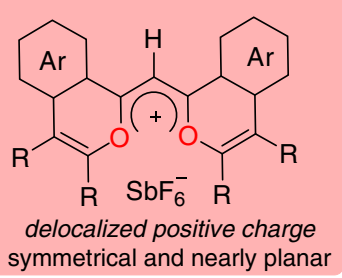

Butterfly flavylium fluorophore (this work)

Fig. 1 Representative organic fluorophores. a Nitrogen-based fluorophores. b Oxygen-based fluorophores. 
tetrahydrofuran, 1, 4-dioxane, and $\mathrm{N}, \mathrm{N}$-dimethylformamide did not deliver the product (Supplementary Table 1, entries 17-20). The yield of 3aa could reach $73 \%$ by decreasing the temperature from 150 to $100^{\circ} \mathrm{C}$ (Supplementary Table 1, entry 24).

Substrate scope. To assemble a structurally diverse library of the BFFs, the substrate scope was conducted. As shown in Fig. 4, the cascade annulation of (hetero)aryl ketones with alkynes allowed a relatively broad substrate scope, producing a diverse family of BFFs in moderate to good yields. The aryl ketones with an electron-donating group at the para position such as $\mathrm{N}, \mathrm{N}$-dimethyl could deliver the desired fluorophore (3ba) in 39\% yield. 3Methylacetophenone and 3,4-dimethoxyacetophenone could give the corresponding fluorophores, but the pure products were not obtained because of their instability during column chromatography. Delightedly, the heteroaryl ketones such as 2-acetylthiophene, 2-acetylbenzo[b]thiophene, 2-acetylbenzo[b]furan, and 3 -acetylbenzo[b]thiophene could afford the corresponding fluorophores (3da-3ga) in moderate yields. The good compatibility of heteroaryl ketones enriches the structural diversity. Next, the scope of the alkyne derivatives was investigated. The electron-donating group such as methyl and methoxy could be tolerated, producing the desired products (3ab-3ac) in moderate to good yields. The

a Our work<smiles>[R]C#C[3H]</smiles>

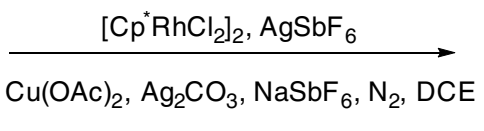

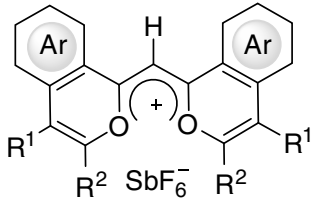

b Proposed reaction pathway:<smiles>CC(C)CC(C)C(=O)c1ccccc1C(C)C</smiles>

Rh catalysis
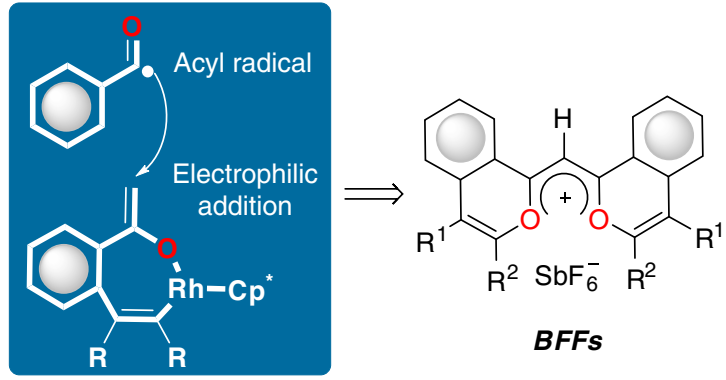

BFFs

Fig. 2 Merging radical chemistry with C-H activation to construct BFFs. a In this report, one step synthesis of BFFs. b The proposed reaction pathway.

a

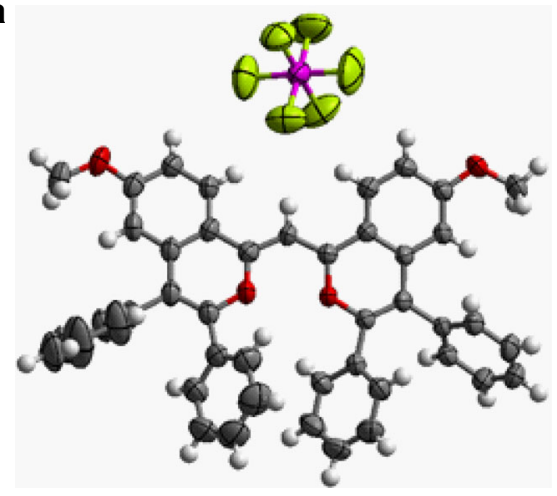

c

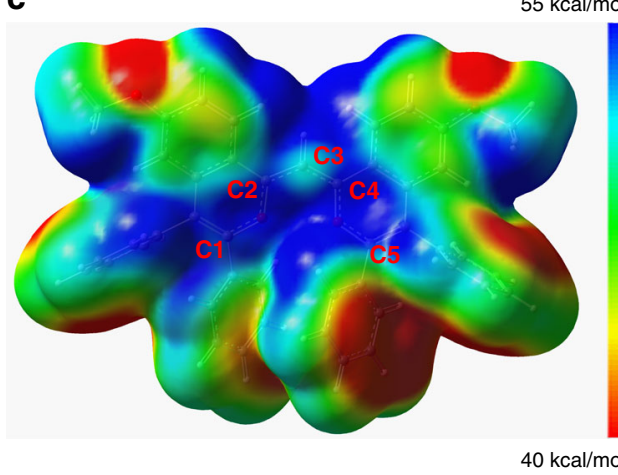

b

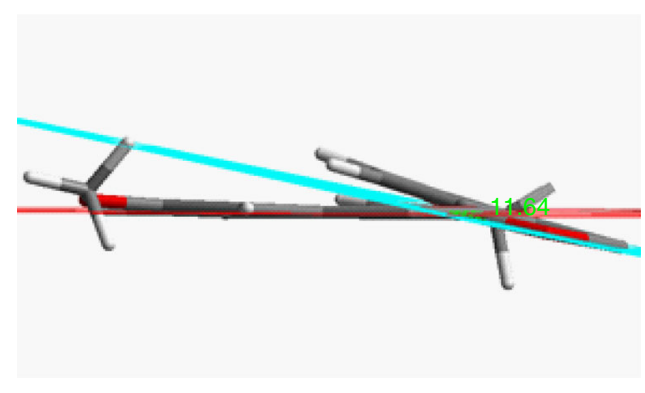

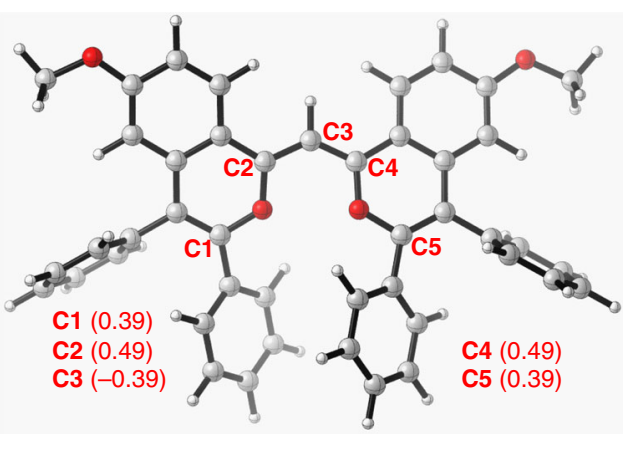

Fig. 3 X-ray single crystal diffraction analysis and DFT calculation of 3aa. a Top view of X-ray single crystal structure of 3aa. b Side view of X-ray single crystal structure of 3aa. c Electrostatic potential maps of 3aa. d Calculated NBO atomic charge distribution of cationic 3aa. 


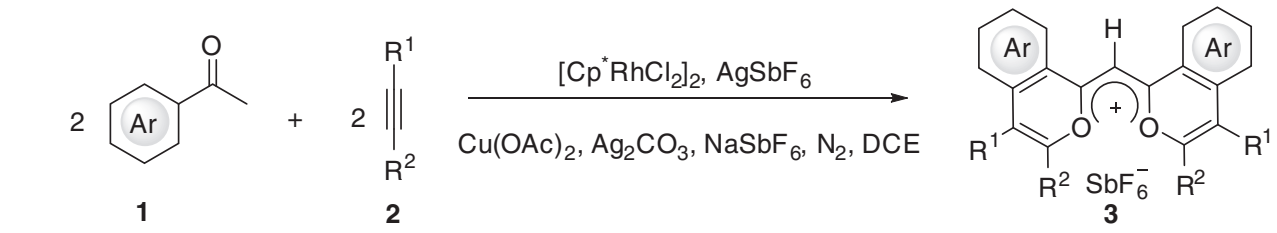<smiles></smiles>

3aa, $73 \%$<smiles>CN(C)c1ccc2c(c1)C(c1ccccc1)=C(c1ccccc1)Oc1cc-2c(-c2ccccc2)c(-c2ccccc2)c1-c1ccccc1</smiles>

3ba, $39 \%^{\dagger}$<smiles></smiles>

3 ca, $40 \%^{\ddagger}$<smiles></smiles>

$3 \mathrm{da}, 38 \%$<smiles></smiles>

3ea, $55 \%$<smiles></smiles>

3fa, $40 \%$<smiles></smiles>

3ga, $59 \%$<smiles></smiles>

$R^{1}=R^{2}=3-M_{e C} \mathrm{H}_{4}, 3 a b, 75 \%$

$\mathrm{R}^{1}=\mathrm{R}^{2}=4-\mathrm{MeOC}_{6} \mathrm{H}_{4}, 3 \mathrm{ac}, 50 \%$

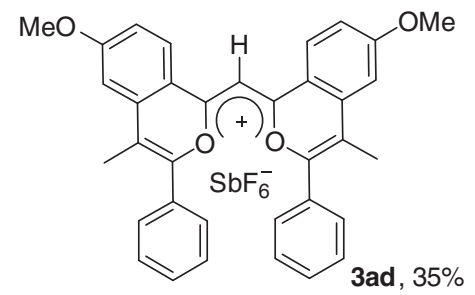

Fig. 4 Substrate scope. Reaction conditions: $\left.1(0.2 \mathrm{mmol}), 2(0.3 \mathrm{mmol}),\left[\mathrm{Cp}^{\star} \mathrm{RhCl}_{2}\right]_{2}(5 \mathrm{~mol} \%), \mathrm{AgSbF}{ }_{6}(2 \mathrm{Omol} \%), \mathrm{Ag}_{2} \mathrm{CO}_{3}(0.3 \mathrm{mmol}), \mathrm{Cu}(\mathrm{OAc})\right)_{2} \cdot \mathrm{H}_{2} \mathrm{O}$ (0.04 mmol), $\mathrm{NaSbF}_{6}(0.15 \mathrm{mmol})$, and DCE $(0.5 \mathrm{~mL})$ at $100^{\circ} \mathrm{C}$ for $12 \mathrm{~h}$ under $\mathrm{N}_{2}{ }^{\dagger} \mathrm{At} 75^{\circ} \mathrm{C}$ for $4 \mathrm{~h}$. $\$$ At $150^{\circ} \mathrm{C}$.

unsymmetrical alkyl aryl alkyne delivered 3ad with a good regioselectivity and other isomers were not detected.

Mechanism of investigation. To get a clearer perception of this cascade process, a set of control experiments were performed (Fig. 5). Firstly, under the standard reaction conditions, acetophenone, respectively, delivered the BFF $3 \mathrm{ca}$ in $22 \%$ yield at $100{ }^{\circ} \mathrm{C}$ and $40 \%$ yield at $150^{\circ} \mathrm{C}$, while 1,3-diphenylpropane1,3-dione did not deliver the corresponding product either at 100 or $150^{\circ} \mathrm{C}$ (Fig. 5a, b). These results indicated that 1,3-dicarbonyl compound was not the intermediate of this reaction. Secondly, under otherwise identical reaction conditions, the absence of counteranion source $\mathrm{NaSbF}_{6}$ led to $3 \mathbf{a a}$ in $12 \%$ yield and the fulvene derivative $4 \mathbf{a a}$ in $28 \%$ yield (Fig. $5 \mathrm{c}$ ). Under the standard reaction conditions, the reaction of $\mathbf{1 a}$ with $\mathbf{2 a}$ could deliver a trace amount of the fulvene derivative 4aa. The formation of $4 \mathbf{a a}$ demonstrated that the $\mathrm{C} 2-\mathrm{H}$ activation process of arylketone existed in this reaction system. The ESI-HRMS experiment did not detect 5aa, implying that the cascade reaction might be a successive process rather than a step by step process (Fig. 5c). In a step by step process, a stable reaction intermediate could be isolated through condition control and the final product could be obtained in an acceptable yield by using the reaction intermediate as the starting material. Thirdly, under the standard reaction conditions, the reaction of 1a, 2a, and 4-methoxybenzoyl formic acid gave a mixture of $3 \mathbf{c a}$ and the unsymmetric product $\mathbf{6 c a}$, which was detected by ESI-HRMS (Fig. 5d and Supplementary Fig. 3). This result suggested that the benzoylformic acid could be one of the reaction intermediates and the deprivation of the carbon atom could be related to the decarboxylation process.

Based on the above results, we infer that this transformation might involve two main processes: (a) the generation of rhodacycle by the $\mathrm{C} 2-\mathrm{H}$ activation of arylketone; and (b) the generation of acyl radical by the oxidation/decarboxylation sequence of arylketone. To gain more insights into the radical process, radical trapping experiments were carried out. The yield of 3aa decreased from $52 \%$ to trace with increasing amount of radical quencher (2,2,6,6-tetramethylpiperidin-1-yl)oxyl (TEMPO), suggesting the possible radical pathway (Fig. 6a and Supplementary Table 2). Subsequently, EPR analysis indicated that the reaction of $1 \mathbf{a}$ with 2a was EPR-active, while no signals were observed in the absence of both 1a and 2a (Fig. 6b, c and Supplementary Fig. 6a, b). Under the standard reaction conditions, the product 3 aa had only a weak EPR signal (Supplementary Fig. 6c). Furthermore, the reaction of 1e, 2a and TEMPO could deliver the isocoumarin product 7ea in $39 \%$ yield, while only a trace amount of 7 ea could be detected without the addition of TEMPO (Fig. 6d). This result indicated that the adduct of acyl radical with TEMPO could be the reaction intermediate for the generation of 7ea (for details, see Supplementary Fig. 4). In addition, without the addition of catalyst $\left[\mathrm{Cp}^{*} \mathrm{RhCl}_{2}\right]_{2}$, the reaction of $\mathbf{1 e}, \mathbf{2 a}$ and TEMPO could produce 8ea in $18 \%$ yield, demonstrating the generation of acyl radical (Fig. 6e and Supplementary Fig. 5). These results clearly demonstrated that the acyl radical species is involved in the cascade reaction.

Based on the experimental observations and the reported literature, the reaction pathway is proposed in Fig. 7. Firstly, the 
a

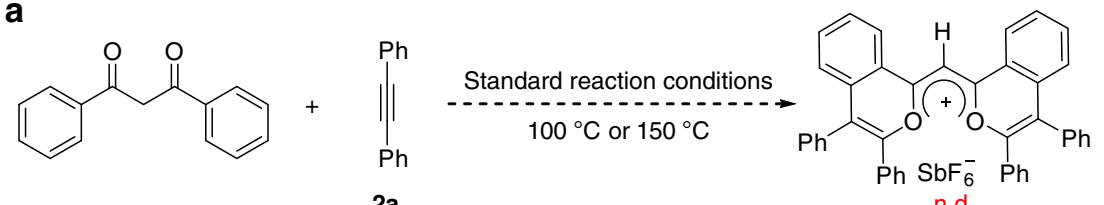

2a

n.d.

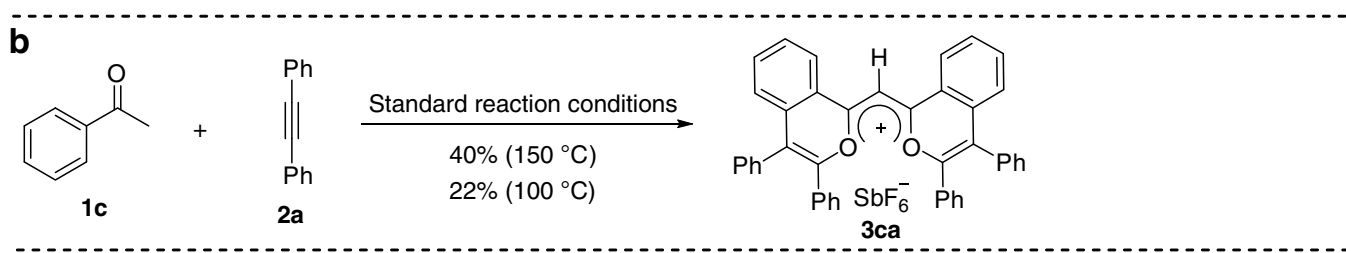

1a

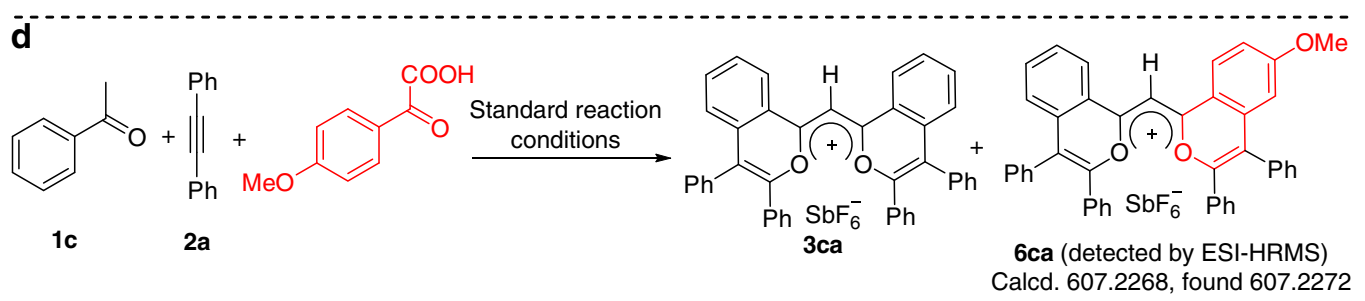

Fig. 5 Control experiments for the reaction mechanism. a The reaction of 1,3-diphenylpropane-1,3-dione with $\mathbf{2 a}$ was performed under standard reaction conditions. $\mathbf{b}$ The reaction of $\mathbf{1 c}$ with $\mathbf{2 a}$ was performed under the standard reaction conditions at 100 or $150{ }^{\circ} \mathrm{C}$. $\mathbf{c}$ The reaction of $\mathbf{1 a}$ with $\mathbf{2} \mathbf{a}$ was performed without the addition of the extra anion source $\mathrm{NaSbF}_{6}$. $\mathbf{d}$ The reaction of $\mathbf{1 c}, \mathbf{2} \mathbf{a}$, and 4-methoxybenzoyl formic acid was performed under the standard reaction conditions.
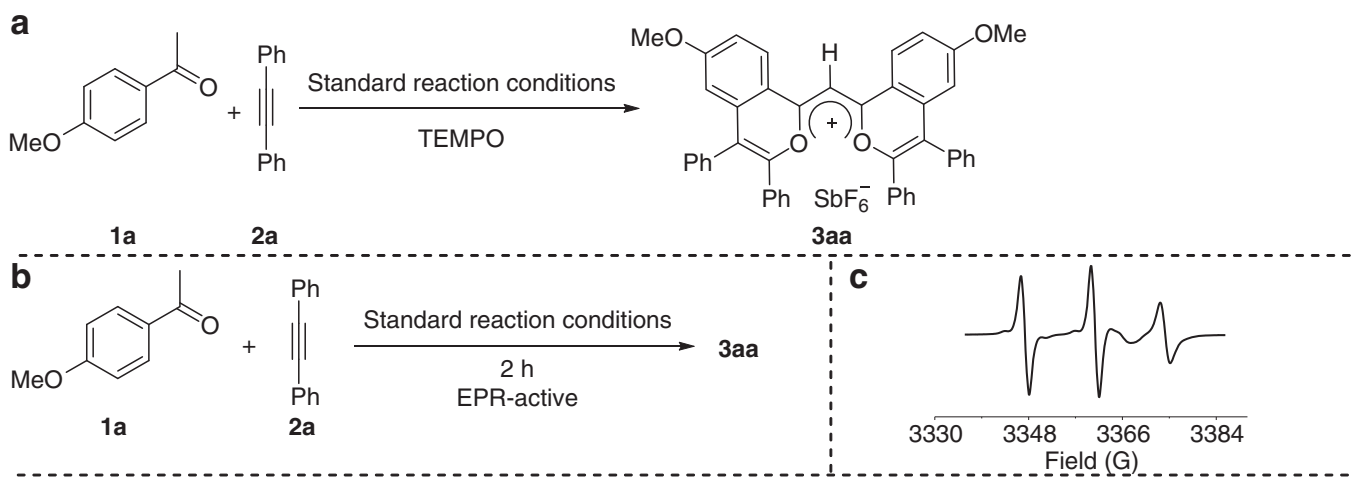

d<smiles>CC(=[O+]c1ccccc1)c1cc2ccccc2s1</smiles>

$1 e$

2a

via
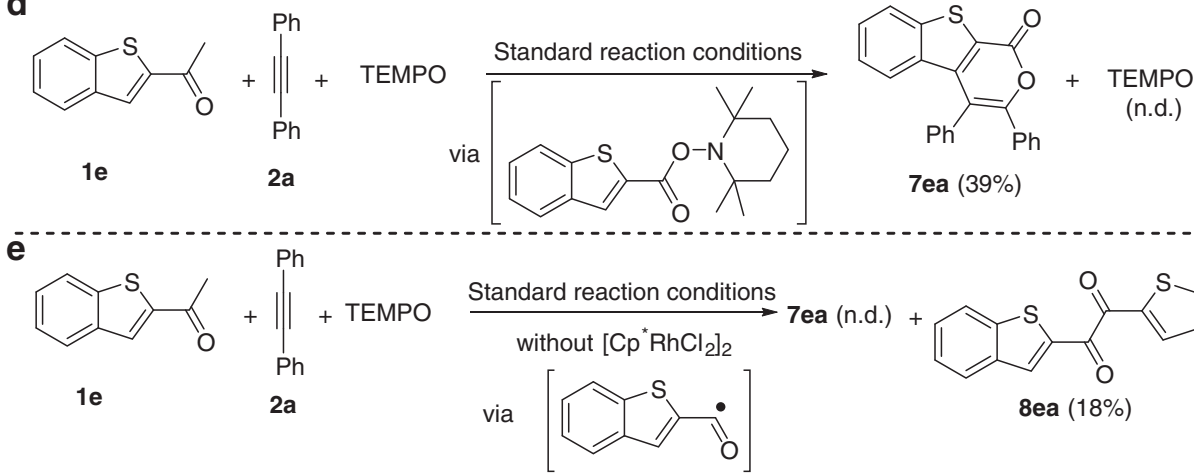

7ea $(39 \%)$

Fig. 6 Detection of radical intermediates. a Radical trapping experiments. $\mathbf{b}$ EPR experiments of the reaction 1a with $\mathbf{2 a}$. $\mathbf{c}$ EPR spectrum of the reaction mixture of $\mathbf{1} \mathbf{a}$ and $\mathbf{2} \mathbf{a}$ under standard reaction conditions. $\mathbf{d}$ The reaction of $\mathbf{1 e}, \mathbf{2} \mathbf{a}$, and TEMPO under the standard reaction conditions. $\mathbf{e}$ The reaction of $\mathbf{1 e}$ $\mathbf{2 a}$, and TEMPO without the addition of catalyst $\left[\mathrm{Cp}^{\star} \mathrm{RhCl}_{2}\right]_{2}$. 


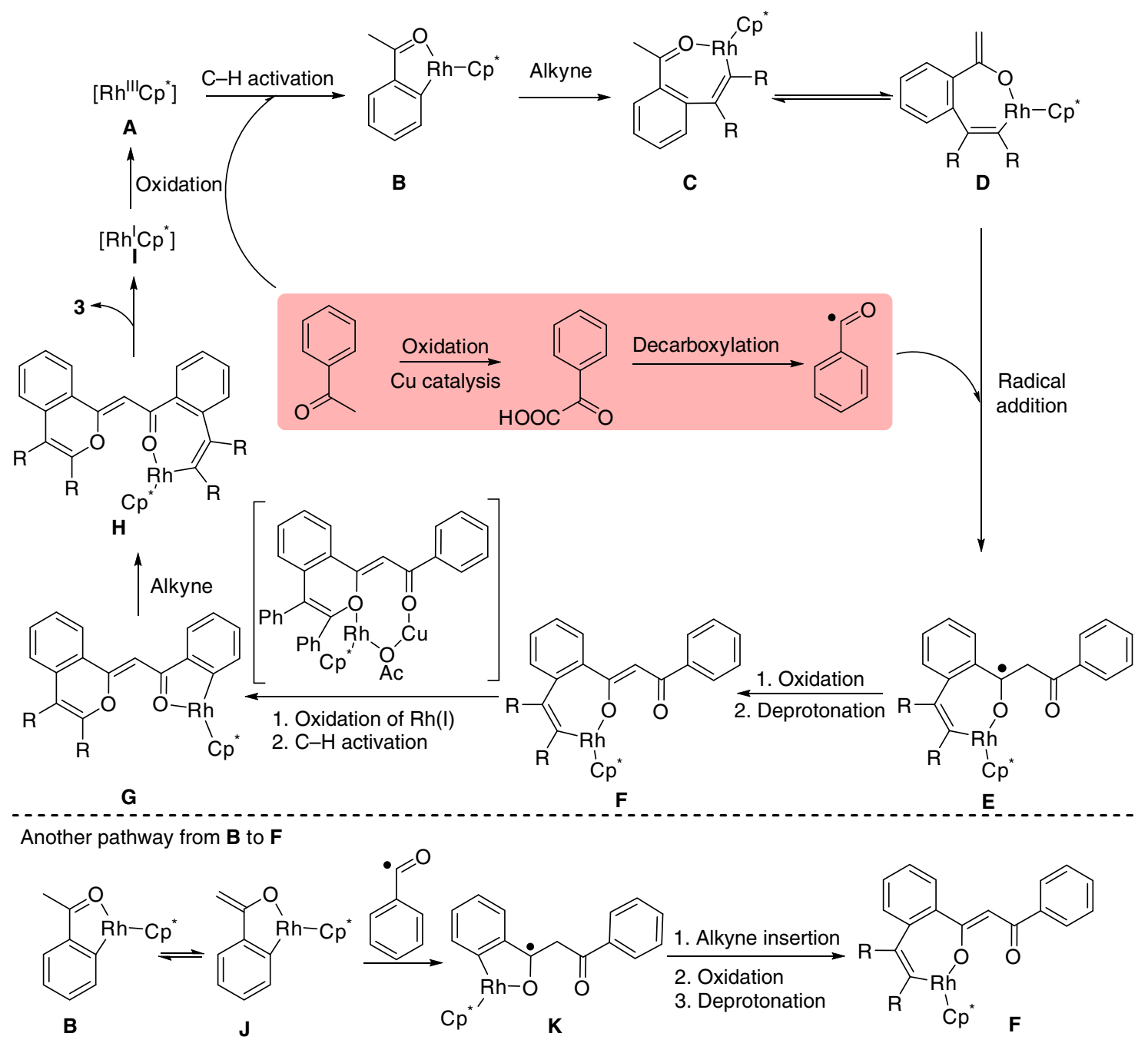

Fig. 7 Plausible catalytic cycle. The possible mechanism involves the Rh-catalyzed $\mathrm{C} 2-\mathrm{H}$ activation of aryl ketone to generate the rhadocycle and the $\mathrm{Cu}$ catalyzed oxidation/C-C bond cleavage of aryl ketone to produce the acyl radical.

reactive $\left[\mathrm{Rh}^{\mathrm{III}} \mathrm{Cp}^{*}\right] \mathbf{A}$ is formed via the reaction of $\left[\mathrm{Cp}^{*} \mathrm{RhCl}_{2}\right]_{2}$ with $\mathrm{AgSbF}_{6}$, followed by the cyclometalation and alkyne insertion. The resulting intermediate $\mathbf{C}$ could undergo a keto-enol tautomerism to generate the intermediate $\mathbf{D}$, which is more easily to be trapped by a radical species. At the same time, the (hetero)aryl ketone is oxidized to (hetero)aryl glyoxylic acid, followed by the generation of acyl radical through a decarboxylation under copper catalysis 39,40 . The selective electrophilic addition of the acyl radical to the rhodacycle $\mathbf{D}$ gives the radical species $\mathbf{E}$, followed by the sequential oxidation and deprotonation process to form intermediate $\mathbf{F}$. In the synthesis of indenol and fulvene derivatives reported by Glorius, the catalytic $\mathrm{Cu}$ $(\mathrm{OAc})_{2} \cdot \mathrm{H}_{2} \mathrm{O}$ plays the role in the release of the rhodium catalyst in a transmetalation event ${ }^{20}$. We propose that one of the key roles of $\mathrm{Cu}(\mathrm{OAc})_{2} \cdot \mathrm{H}_{2} \mathrm{O}$ is to promote the intramolecular rhodium migration, accompanied by the oxidation of $\mathrm{Rh}(\mathrm{I})$ to $\mathrm{Rh}(\mathrm{III})$ and the $\mathrm{C}-\mathrm{H}$ activation of another (hetero)arylketone to form intermediate $\mathbf{G}$. The second alkyne inserts into $\mathbf{G}$ to produce $\mathbf{H}$, followed by a reductive elimination to yield the butterfly flavylium fluorophore. By the oxidation of $\mathrm{Ag}_{2} \mathrm{CO}_{3}$, the active $\mathrm{Rh}$ (III) species is regenerated. There is another possible pathway from intermediate $\mathbf{B}$ to $\mathbf{F}$ as shown in Fig. 7. The acyl radical may attack the intermediate $\mathbf{J}$ generated by a keto-enol tautomerism of $\mathbf{B}$ prior to the first alkyne insertion.
Photophysical properties of BFFs. With the diverse BFFs in hand, the photophysical properties of fluorophores, including UV-Vis absorption, fluorescence emission, extinction coefficients, excitation, and quantum yield, were measured in $\mathrm{CH}_{2} \mathrm{Cl}_{2}$ (Supplementary Table 3 and Supplementary Fig. 7). As shown in Fig. 8 and Supplementary Table 3, the BFFs show tunable absorption and emission wavelengths and high quantum yields in $\mathrm{CH}_{2} \mathrm{Cl}_{2}$. The quantum yields of the fluorophores $3 \mathbf{c a}, 3 \mathbf{e a}, 3 \mathbf{f a}$, and 3ac could reach $46 \%, 59 \%, 63 \%$, and $49 \%$ even with emission maxima of $626,656,660$, and $631 \mathrm{~nm}$, respectively.

\section{Discussion}

In summary, a class of BFFs has been developed through the merging of $\mathrm{C}-\mathrm{H}$ activation and radical chemistry. Because both (hetero)arylketones and alkynes are easily available and structurally diverse, the structures of the BFFs are easily subjected to chemical modification. These fluorophores exhibit intriguing photophysical properties, such as tunable absorption and emission wavelengths, high quantum yield and zwitterionic form, rendering them potential applications as luminescence materials. The rapid gateway to BFFs described herein has further exemplified the power of the combination of $\mathrm{C}-\mathrm{H}$ activation and radical chemistry in the exploration of organic functional materials. 

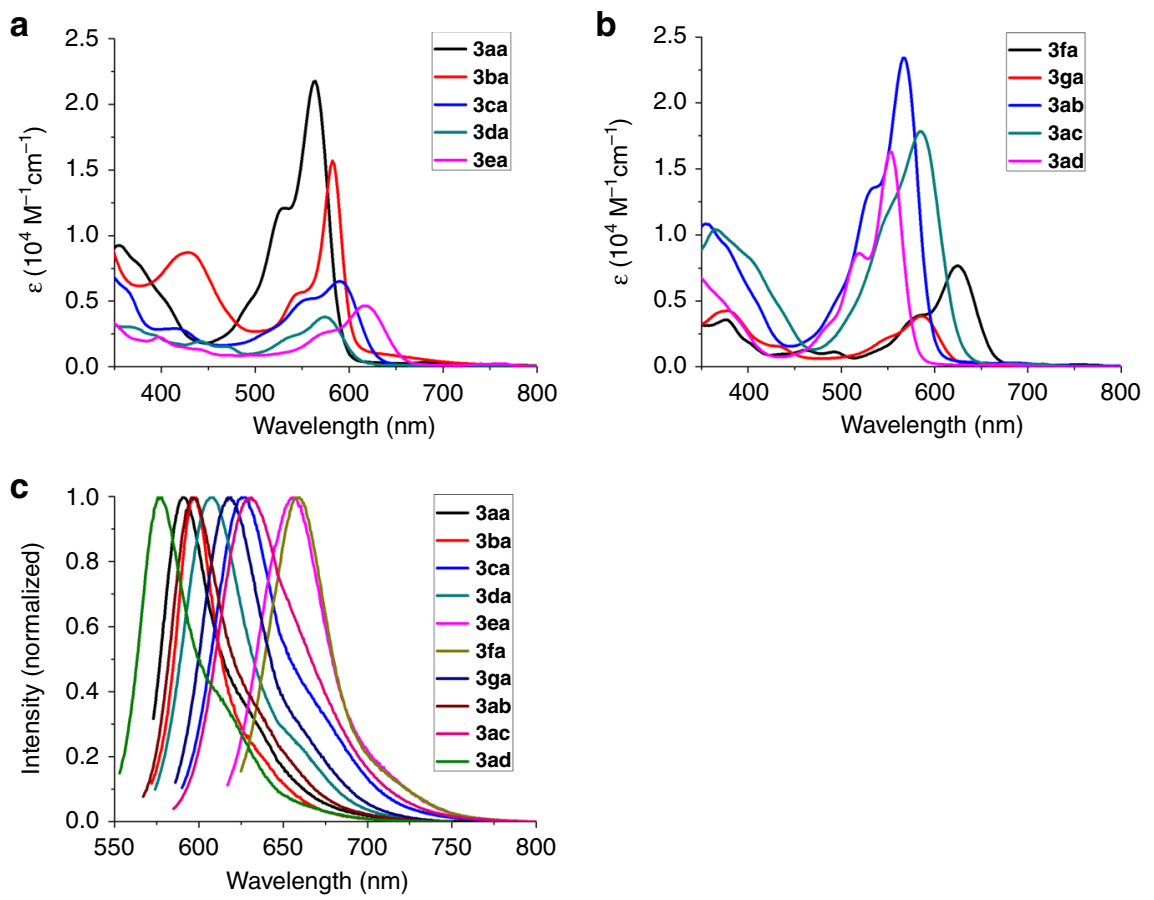

Fig. 8 Absorption and emission spectra of the BFFs in $\mathbf{C H}_{2} \mathbf{C l}_{\mathbf{2}}$ at $\mathbf{4 0 . 0} \mu \mathbf{M}$. a The absorption spectra of 3aa, 3ba, 3ca, 3da, and 3ea. b The absorption spectra of 3fa, 3ga, 3ab, 3ac and 3ad. c The emission spectra of all BFFs.

\section{Methods}

General procedure for the synthesis of BFFs. A Schlenk tube with a magnetic stir bar was charged with $\left[\mathrm{Cp}^{\star} \mathrm{RhCl}_{2}\right]_{2}(0.005 \mathrm{mmol}), \mathrm{AgSbF}_{6}(0.02 \mathrm{mmol}), \mathrm{Ag}_{2} \mathrm{CO}_{3}$ $(0.3 \mathrm{mmol}), \mathrm{Cu}(\mathrm{OAc})_{2} \cdot \mathrm{H}_{2} \mathrm{O}(0.04 \mathrm{mmol}), \mathrm{NaSbF}_{6}(0.15 \mathrm{mmol})$, arylketone $(0.2 \mathrm{mmol})$, alkyne $(0.3 \mathrm{mmol})$, and DCE $(0.5 \mathrm{~mL})$ under an $\mathrm{N}_{2}$ atmosphere. The resulting solution was stirred at room temperature for $10 \mathrm{~min}$ and then at the indicated temperature for the indicated time. The resulting solution was cooled to ambient temperature, diluted with $10 \mathrm{~mL}$ of dichloromethane. The obtained organic extracts was evaporated under reduced pressure and the residue was absorbed into small amounts of silica gel. Purification was performed by column chromatography on silica gel to provide product 3 . The reaction vessel is under pressure and could possibly explode because of higher reaction temperature than the boiling point of DCE.

\section{Data availability}

Experimental procedures and characterization data are available within this article and Supplementary Information. The X-ray crystallographic coordinates for structures reported in this article have been deposited at the Cambridge Crystallographic Data Centre (CCDC) under deposition numbers CCDC 1914708 (3aa) and CCDC 1917431 (3ad). These data can be obtained free of charge from The Cambridge Crystallographic Data Centre via www.ccdc.cam.ac.uk/data_request/cif.

Received: 1 August 2019; Accepted: 8 November 2019; Published online: 11 December 2019

\section{References}

1. Ethirajan, M., Chen, Y., Joshy, P. \& Pandey, R. K. The role of porphyrin chemistry in tumor imaging and photodynamic therapy. Chem. Soc. Rev. 40, 340-362 (2011).

2. Tanaka, T. \& Osuka, A. Conjugated porphyrin arrays: synthesis, properties and applications for functional materials. Chem. Soc. Rev. 44, 943-969 (2015).

3. Burgess, K. \& Loudet, A. BODIPY dyes and their derivatives: syntheses and spectroscopic properties. Chem. Rev. 107, 4891-4932 (2007).

4. Ulrich, G., Ziessel, R. \& Harriman, A. The chemistry of fluorescent bodipy dyes: versatility unsurpassed. Angew. Chem. Int. Ed. 47, 1184-1201 (2008).

5. Jean-Gérard, L., Vasseur, W., Scherninskib, F. \& Andrioletti, B. Recent advances in the synthesis of [a]-benzo-fused BODIPY fluorophores. Chem. Commun. 54, 12914-12929 (2018).

6. Mishra, A., Behera, R. K., Behera, P. K., Mishra, B. K. \& Behera, G. B. Cyanines during the 1990s: a review. Chem. Rev. 100, 1973-2011 (2000)
7. Sun, W., Guo, S., Hu, C., Fan, J. \& Peng, X. Recent development of chemosensors based on cyanine platforms. Chem. Rev. 116, 7768-7817 (2016).

8. Wu, D., Pisula, W., Haberecht, M. C., Feng, X. \& Müllen, K. Oxygen- and sulfur-containing positively charged polycyclic aromatic hydrocarbons. Org. Lett. 11, 5686-5689 (2009).

9. Rao, K. P. et al. Double protonation of 1,5-bis(triarylaminoethynyl) anthraquinone to form a paramagnetic pentacyclic dipyrylium salt. J. Am. Chem. Soc. 132, 12472-12479 (2010).

10. Anamimoghadam, O. et al. Electronically stabilized nonplanar phenalenyl radical and its planar isomer. J. Am. Chem. Soc. 137, 14944-14951 (2015).

11. Cheng, D. et al. Selective visualization of the endogenous peroxynitrite in an inflamed mouse model by a mitochondria-targetable two-photon ratiometric fluorescent probe. J. Am. Chem. Soc. 139, 285-292 (2017).

12. Cosco, E. D. et al. Flavylium polymethine fluorophores for near- and shortwave infrared imaging. Angew. Chem. Int. Ed. 56, 13126-13129 (2017).

13. Lei, Z. et al. Stable, wavelength-tunable fluorescent dyes in the NIR-II region for in vivo high-contrast bioimaging and multiplexed biosensing. Angew. Chem. Int. Ed. 58, 8166-8171 (2019).

14. Colby, D. A., Bergman, R. G. \& Ellman, J. A. Rhodium-catalyzed C-C bond formation via heteroatom-directed $\mathrm{C}-\mathrm{H}$ bond activation. Chem. Rev. 110, 624-655 (2010).

15. Song, G., Wang, F. \& $\mathrm{Li}, \mathrm{X}$. C-C, C-O and $\mathrm{C}-\mathrm{N}$ bond formation via rhodium (III)-catalyzed oxidative C-H activation. Chem. Soc. Rev. 41, 3651-3678 (2012).

16. Yang, Y. et al. Rhodium-catalyzed annulation of arenes with alkynes through weak chelation-assisted C-H activation. Chem. Commun. 52, 2872-2884 (2016).

17. Yang, Y., Lan, J. \& You, J. Oxidative C-H/C-H coupling reactions between two (hetero)arenes. Chem. Rev. 117, 8787-8863 (2017).

18. Stuart, D. R., Alsabeh, P., Kuhn, M. \& Fagnou, K. Rhodium(III)-catalyzed arene and alkene $\mathrm{C}-\mathrm{H}$ bond functionalization leading to indoles and pyrroles. J. Am. Chem. Soc. 132, 18326-18339 (2010).

19. Mochida, S., Shimizu, M., Hirano, K., Satoh, T. \& Miura, M. Synthesis of naphtho[1,8-bc]pyran drivatives and related cmpounds through hydroxy group directed $\mathrm{C}-\mathrm{H}$ bond cleavage under rhodium catalysis. Chem. Asian J. 5, 847-851 (2010).

20. Patureau, F. W., Besset, T., Kuhl, N. \& Glorius, F. Diverse strategies toward indenol and fulvene derivatives: Rh-catalyzed $\mathrm{C}-\mathrm{H}$ activation of aryl ketones followed by coupling with internal alkynes. J. Am. Chem. Soc. 133, 2154-2156 (2011).

21. Muralirajan, K., Parthasarathy, K. \& Cheng, C.-H. Regioselective synthesis of indenols by rhodium-catalyzed $\mathrm{C}-\mathrm{H}$ activation and carbocyclization of aryl ketones and alkynes. Angew. Chem. Int. Ed. 50, 4169-4172 (2011). 
22. Tan, $\mathrm{X}$. et al. Rhodium-catalyzed cascade oxidative annulation leading to substituted naphtho[1,8-bc]pyrans by sequential cleavage of $\mathrm{C}\left(\mathrm{sp}^{2}\right)-\mathrm{H} / \mathrm{C}\left(\mathrm{sp}^{3}\right)-\mathrm{H}$ and $\mathrm{C}\left(\mathrm{sp}^{2}\right)-\mathrm{H} / \mathrm{O}-\mathrm{H}$ bonds. J. Am. Chem. Soc. 134, 16163-16166 (2012).

23. Liu, X., Li, G., Song, F. \& You, J. Unexpected regioselective carbon-hydrogen bond activation/cyclization of indolyl aldehydes or ketones with alkynes to benzo-fused oxindoles. Nat. Commun. 5, 5030 (2014).

24. Yin, J. et al. Synthesis of phenalenyl-fused pyrylium cations: divergent $\mathrm{C}-\mathrm{H}$ activation/annulation reaction sequence of naphthalene aldehydes with alkynes. Angew. Chem. Int. Ed. 56, 13094-13098 (2017).

25. Yin, J. et al. Annulation cascade of arylnitriles with alkynes to stable delocalized PAH carbocations via intramolecular rhodium migration. Chem. Sci. 9, 5488-5493 (2018).

26. Yu, J.-T. \& Pan, C. Radical C-H functionalization to construct heterocyclic compounds. Chem. Commun. 52, 2220-2236 (2016).

27. Yan, M., Lo, J. C., Edwards, J. T. \& Baran, P. S. Radicals: reactive intermediates with translational potential. J. Am. Chem. Soc. 138, 12692-12714 (2016).

28. Yi, H. et al. Recent advances in radical $\mathrm{C}-\mathrm{H}$ activation/radical cross-coupling. Chem. Rev. 117, 9016-9085 (2017).

29. Huang, Z. et al. Iron-catalyzed oxidative radical cross-coupling/cyclization between phenols and olefins. Angew. Chem. Int. Ed. 52, 7151-7155 (2013).

30. Chen, F. et al. Dehydrogenative $\mathrm{N}$-incorporation: a direct approach to quinoxaline $\mathrm{N}$-oxides under mild conditions. Angew. Chem. Int. Ed. 53, 10495-10499 (2014).

31. Tomakinian, T., Guillot, R., Kouklovsky, C. \& Vincent, G. Direct oxidative coupling of N-acetyl indoles and phenols for the synthesis of benzofuroindolines related to phalarine. Angew. Chem. Int. Ed. 53, 11881-11885 (2014).

32. Cotugno, P., Monopoli, A., Ciminale, F., Milella, A. \& Nacci, A. Palladiumcatalyzed cross-coupling of styrenes with aryl methyl ketones in ionic liquids: direct access to cyclopropanes. Angew. Chem. Int. Ed. 53, 13563-13567 (2014).

33. Manna, S. \& Antonchick, A. P. Copper-catalyzed $(2+1)$ annulation of acetophenones with maleimides: direct synthesis of cyclopropanes. Angew. Chem. Int. Ed. 54, 14845-14848 (2015).

34. Le, C., Chen, T. Q., Liang, T., Zhang, P. \& MacMillan, D. W. C. A radical approach to the copper oxidative addition problem: trifluoromethylation of bromoarenes. Science 360, 1010-1014 (2018).

35. Yin, J. \& You, J. Concise synthesis of polysubstituted carbohelicenes by a C-H activation/radical reaction/C-H activation sequence. Angew. Chem. Int. Ed. 58, 302-306 (2019).

36. Allen, F. H. et al. Tables of bond lengths determined by X-ray and neutron diffraction. Part I. bond lengths in organic compounds. J. Chem. Soc. Perkin Trans. 2, S1-S19 (1987).

37. Reed, A. E., Weinstock, R. B. \& Weinhold, F. Natural population analysis. J. Chem. Phys. 83, 735-746 (1985).

38. Reed, A. E., Curtiss, L. A. \& Weinhold, F. Intermolecular interactions from a natural bond orbital, donor-acceptor viewpoint. Chem. Rev. 88, 899-926 (1988).

39. Wang, $\mathrm{M}$. et al. Oxidative $\mathrm{C}(\mathrm{OH})-\mathrm{C}$ bond cleavage of secondary alcohols to acids over a copper catalyst with molecular oxygen as the oxidant. J. Catal. 348, 160-167 (2017).
40. Baruah, S., Borthakur, S. \& Gogoi, S. Directing group assisted coppermediated aroylation of phenols using 2-bromoacetophenones. Chem. Commun. 53, 9133-9135 (2017).

\section{Acknowledgements}

The authors acknowledge support for this work from the National NSF of China (Nos. 21772128 and 21432005).

\section{Author contributions}

J.Y. (Yin), Y.Z., J.L., and L.Z. performed the experiments and analyzed the data. Y.L. and J.Y. (You) designed and directed the project and wrote the manuscript. All authors contributed to discussions.

\section{Competing interests}

The authors declare no competing interests.

\section{Additional information}

Supplementary information is available for this paper at https://doi.org/10.1038/s41467019-13611-6.

Correspondence and requests for materials should be addressed to J.Y.

Peer review information Nature Communications thanks Haibo Ge and the other, anonymous, reviewer(s) for their contribution to the peer review of this work.

Reprints and permission information is available at http://www.nature.com/reprints

Publisher's note Springer Nature remains neutral with regard to jurisdictional claims in published maps and institutional affiliations.

Open Access This article is licensed under a Creative Commons Attribution 4.0 International License, which permits use, sharing, adaptation, distribution and reproduction in any medium or format, as long as you give appropriate credit to the original author(s) and the source, provide a link to the Creative Commons license, and indicate if changes were made. The images or other third party material in this article are included in the article's Creative Commons license, unless indicated otherwise in a credit line to the material. If material is not included in the article's Creative Commons license and your intended use is not permitted by statutory regulation or exceeds the permitted use, you will need to obtain permission directly from the copyright holder. To view a copy of this license, visit http://creativecommons.org/ licenses/by/4.0\%

(C) The Author(s) 2019 